\title{
Heterotopic gastric mucosa in the esophagus: Case report and discussion
}

\author{
CY SPREAD, MD, RJ BAILEY, MD
}

CY SPREAD, RJ BAILEY. Heterotopic gastric mucosa in the esophagus: Case report and discussion. Can J Gastroenterol 1993;7(8):589-594. The case of an elderly man with heterotopic gastric mucosa of the cervical esophagus associated with an esophageal web, as well as a discussion of heterotopic gastric mucosa, are presented. The presence of an 'inlet patch' is a common endoscopic finding; about $10 \%$ of the population will have the heterotopic mucosa just below the upper esophageal sphincter. Although there is controversy regarding pathogenesis, a congenital origin is favoured over an acquired lesion. The patches may be single, multiple or circumferential. Histologically, just over half are ectopic gastric fundic mucosa and $90 \%$ of the patches contain both parietal and chief cells. Most patients with the inlet patch remain asymptomatic; about $15 \%$ with have mild pharyngeal discomfort and/or high dysphagia. Symptoms will often accompany the development of a complication, such as ulceration, that may be associated with bleeding, a stricture at the squamocolumnar junction or an esophageal web. Diagnostic manoeuvres to identify the mucosa include barium studies, endoscopy, Congo red staining to visualize acid production and nuclear medicine scans. No treatment is necessary unless complications develop. Complications can be treated successfully with $\mathrm{H}_{2}$ blockers and/or endoscopic dilation. No follow-up appears to be necessary as there is no proof for malignant transformation of the ectopic mucosa.

Key Words: Aberrant gastric mucosa, Ectopic gastric mucosa, Inlet patch, Upper esophageal web

\section{Muqueuse gastrique hétérotope au niveau de l'oesophage : Rapport de cas et discussion}

RÉSUMÉ : Le cas d'un vieillard présentant une muqueuse gastrique hétérotope au niveau de l'oesophage cervical associée au tissu oesophagien est présenté ici, avec une discussion sur la muqueuse gastrique hétérotope. La présence d'enclaves près de l'orifice d'entrée n'est pas un phénomène rare à l'endoscopie; environ $10 \%$ de la population présentera un muqueuse hétérotope juste sous le sphincter oesophagien supérieur. Bien qu'il y ait une controverse au sujet de sa pathogenèse, on privilégie en générale l'étiologie congénitale plutôt qu'acquise. Les enclaves peuvent être uniques ou multiples, ou encore, circonférentielles. Au plan histologique, un peu plus de la moitié proviennent de muqueuse gastrique fundique ectopique et $90 \%$ des enclaves renferment des cellules gastriques principales et

Correspondence: Dr RJ Bailey, Suite 310, 11010-101 Street, Edmonton, Alberta T5H 4B9 Received for publication June 30, 1992. Accepted April 15, 1993
$\mathrm{H}$ ETEROTOPICGASTRICMUCOSA IS a common endoscopic finding in the cervical esophagus if the mucosa lying just beneath the upper esophageal sphincter (UES) is carefully examined. Although patients with an 'inlet patch" are usually asymptomatic, rare complications are identified. The authors report a case of an esophageal web within a patch of heterotopic gastric mucosa (including diagnostic studies and pathology) and briefly discuss this topic.

\section{CASE PRESENTATION}

A 79-year-old man was seen in consultation because of a single episode of dysphagia. The patient was eating when he felt a bolus of meat stick in his throat. The sensation was felt in the throat rather than the chest, and was not accompanied by pain. The sensation continued for $12 \mathrm{~h}$, then completely resolved, and he was able to eat again without any difficulty.

Further questioning revealed that for the previous month, the patient was constantly bothered by a need to clear his throat. Otherwise, he denied any symptoms. He had no past history of ulcers or gastroesophageal reflux disease.

The patient was exceedingly healthy for his age. He had no serious illnesses, previously had minor surgery only and was on no medications. He had smoked one-half to one pack of cigarettes per day for at least 60 years 
bordantes. La plupart des patients porteurs de telles enclaves demeurent asymptomatiques; environ $15 \%$ souffriront d'un léger inconfort pharyngé ou d'une importante dysphagie. Les symptômes accompagneront souvent le développement d'une complication, comme l'ulcération, avec possiblement hémorragie et strictures à la jonction des cellules épidermoïdes et des cellules à plateau strié ou du tissu oesophagien. Les techniques diagnostiques pour identifier la muqueuse incluent les épreuves au baryum, l'endoscopie et la coloration au rouge Congo pour visualiser la production d'acide et les scintigraphies en médecine nucléaire. Aucun traitement n'est nécessaire à moins que n'apparaissent des complications. Les complications peuvent être traitées avec succès à l'aide d'anti- $\mathrm{H}_{2}$ ou de dilatations endoscopiques. Aucun suivi ne semble nécessaire puisque rien ne tend à démontrer qu'il y aurait évolution vers une néoplasie à partir de muqueuses ectopiques.

and usually had one drink per day. Prior to retiring from work, he had been a carpenter.

Physical examination revealed a thin man in excellent shape. The examination was completely normal.

Investigations: The initial investigation was a barium swallow. This study revealed a small web on the left side of the esophagus at the region of the thoracic inlet and, just inferior to the web, a small area of circumferential narrowing of the esophagus with ulceration anteriorly. The lower esophagus was normal with no evidence of hiatus hernia or reflux (Figure 1).

The next investigation was esophagogastroscopy. The oropharynx was normal. Upon entering the esophagus, gastric mucosa was identified beginning $1 \mathrm{~cm}$ below the UES (Figure 2). The patch of gastric mucosa was circumferential and was $2 \mathrm{~cm}$ in length (19 to $21 \mathrm{~cm}$ from the incisors). At 20 $\mathrm{cm}$, the scope passed through a definite narrowing of the esophagus which resembled a web. The remainder of the esophagus was normal in appearance. The gastroesophageal junction occurred at $39 \mathrm{~cm}$; a small 1 to $2 \mathrm{~cm}$ hiatus hernia was also identified. Biopsies were taken from the normal mucosa above the patch, from the patch and from the gastroesophageal junction. Congo red staining was used to demonstrate acid production by the 'inlet patch'. The patient was given $250 \mu \mathrm{g}$ pentagastrin, and an endoscope was again passed into the esophagus 40 mins later. The patch was first washed with $20 \mathrm{~mL} 4.5 \%$ sodium bicarbonate solution, then irrigated with $10 \mathrm{~mL} 1 \%$ Congo red solution. Ten minutes after the Congo red irrigation, only a very small patch of black stained mucosa was identified (Figure 3), representing a small area of acid production.

Gastric mucosal imaging $(99 \mathrm{~m}$ Tcpertechnetate scintigraphy) was carried out with multiple images of the cervical area and upper thorax. Tomographic imaging and three-dimensional reconstruction revealed an abnormal focus of increased uptake in the upper esophagus behind the lower pole of the thyroid gland. This was thought to represent the area of ectopic gastric mucosa (Figure 4).

Pathology: The presence of a patch of gastric mucosa in the cervical esophagus was confirmed by light microscopy (Figure 5). The inlet patch was likely antral in type (Figure 6), with only occasional parietal cells identified and no chief cells. Immunoperoxidase staining for gastrin, bombesin and somatostatin was carried out. The gastrin and bombesin stains were negative while the biopsies from the mucosal patch stained positively for somatostatin. Mild esophagitis was found in the surrounding squamous mucosa. There was no evidence of esophagitis or Barrett's change in biopsies from the lower esophagus of the patient.

Treatment: The web was easily dilated with a 60 French dilator during the initial esophagogastroscopy. The patient experienced relief from his symptoms after the dilation and remains completely asymptomatic after one year of follow-up.

\section{DISCUSSION}

Heterotopic gastric mucosa has been identified throughout the gastrointestinal tract (oral cavity, esophagus, small bowel, Meckel's diverticula, appendix and rectum) as well as in the gallbladder, pancreas, salivary glands, umbilicus and spinal cord (1). It has also been found in small patches, as the lining of such anomalies as extraintestinal cysts and duplications (2), and in the esophageal pouch of tracheoesophageal fistulas (3).

Incidence: Aberrant gastric mucosa or the inlet patch in the upper third of the esophagus was first described by Schmidt (4) in 1805. According to sporadic reports up to 1927 , the incidence of ectopic gastric mucosa in the esophagus varied from 0.67 to $70 \%$ (5). A 1904 study by Schridde (6) looked at the inlet of the esophagus alone and with minute serial sections. He found heterotopic gastric glands or mucosa in $70 \%$ of patients studied. Most of the glands lay beneath normal squamous mucosa; only $20 \%$ were surface patches (6). Rector and Connerley (5) published the first extensive autopsy study in 1941, examining 1000 infants and children by random section only $-11.8 \%$ of cases had some type of aberrant gastric mucosa present in the esophagus, with $8 \%$ of the lesions within the lower third of the esophagus, $41 \%$ in the middle third, and $51 \%$ in the upper third, and usually at or just below the UES.

More recent studies have attempted to estimate the more useful prevalence of heterotopic gastric mucosa of the esophagus visible to the naked eye. A $10 \%$ incidence of inlet patches was found on gross inspection at autopsy of the esophagi of 300 infants and children aged birth to 14 years (7). Endoscopically, prevalences of 3.8 and $10 \%$ have been found during 420 and 634 consecutive upper gastrointestinal studies, respectively $(8,9)$. Most of the lesions were less than $1 \mathrm{~cm}$ in diameter and asymptomatic, and most were located just below the UES (approximately 15 to $20 \mathrm{~cm}$ from the incisor teeth). The inlet patch in our patient was located in this typical location, just beneath the UES. 


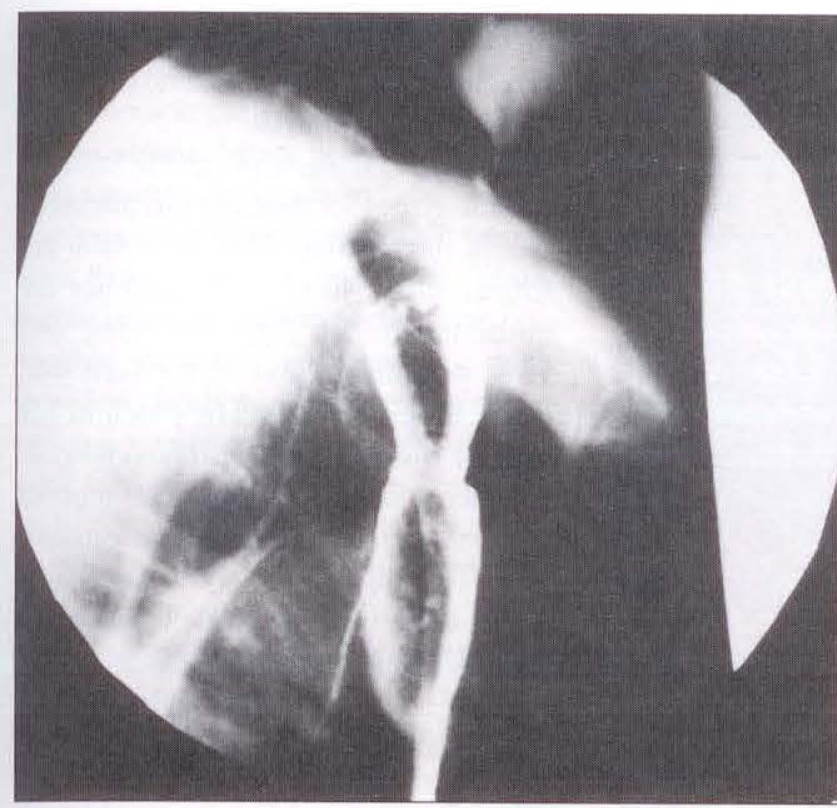

Figure 1) Barium swallow study revealing a small web on the left side of the esophagus at the thoracic inlet and, just inferior to the web, a small area of circumferential narrowing of the esophagus with ulceration anteriorly

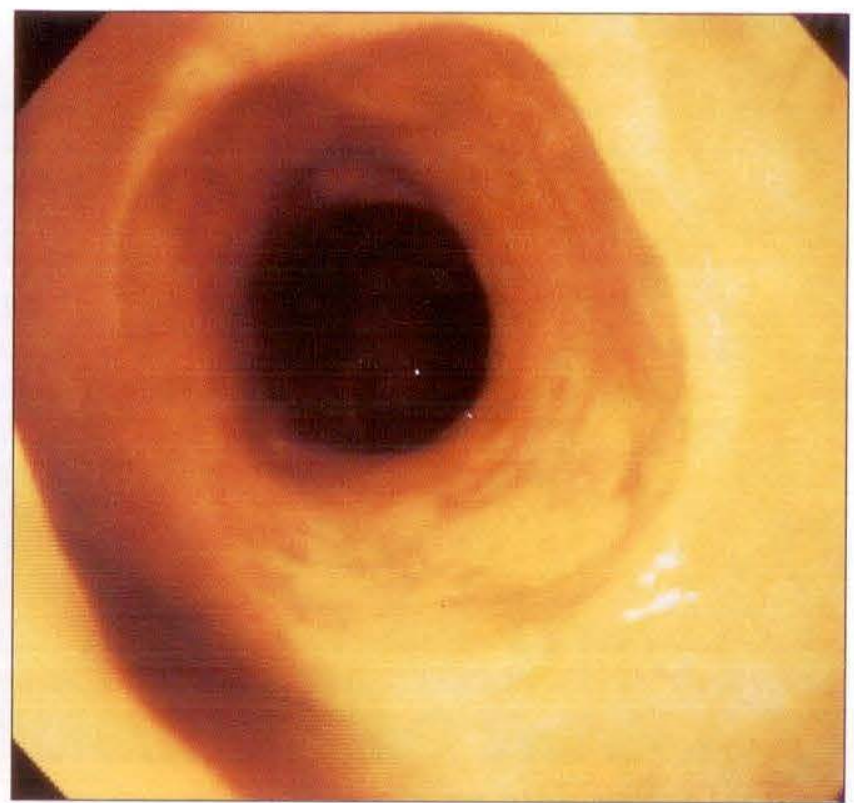

Figure 2) Heterotopic gastric mucosa (inlet patch) in the cervical esophagus showing abrupt junction of gastric and esophageal mucosa

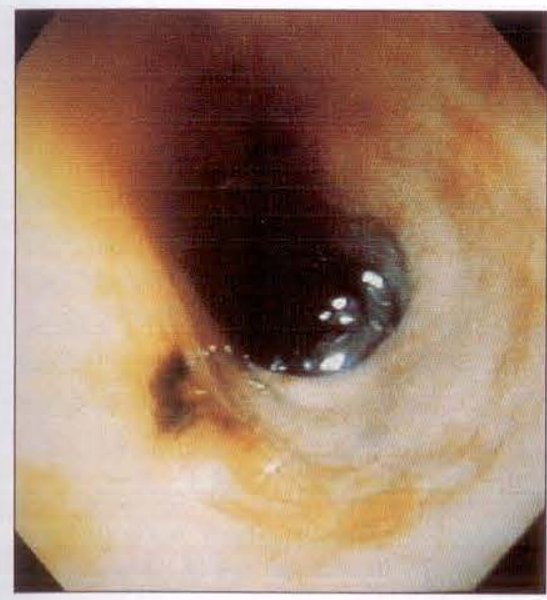

Figure 3) Congo red staining of the inlet patch showing a small area of acid production

Pathogenesis: Controversy has surrounded the pathogenesis of heterotopic gastric mucosa of the esophagus. When located in the lower third of the esophagus, often called Barrett's esophagus, the mucosa appears to be acquired secondary to reflux of gastric acid, injury to the squamous mucosa and metaplasia. For heterotopic gastric mucosa found at the UES, most authors favour a congenital origin, although this has been challenged, especially when concurrent Barrett's esophagus has been identified.

Weaver, a proponent of an acquired origin for heterotopic gastric mucosa,

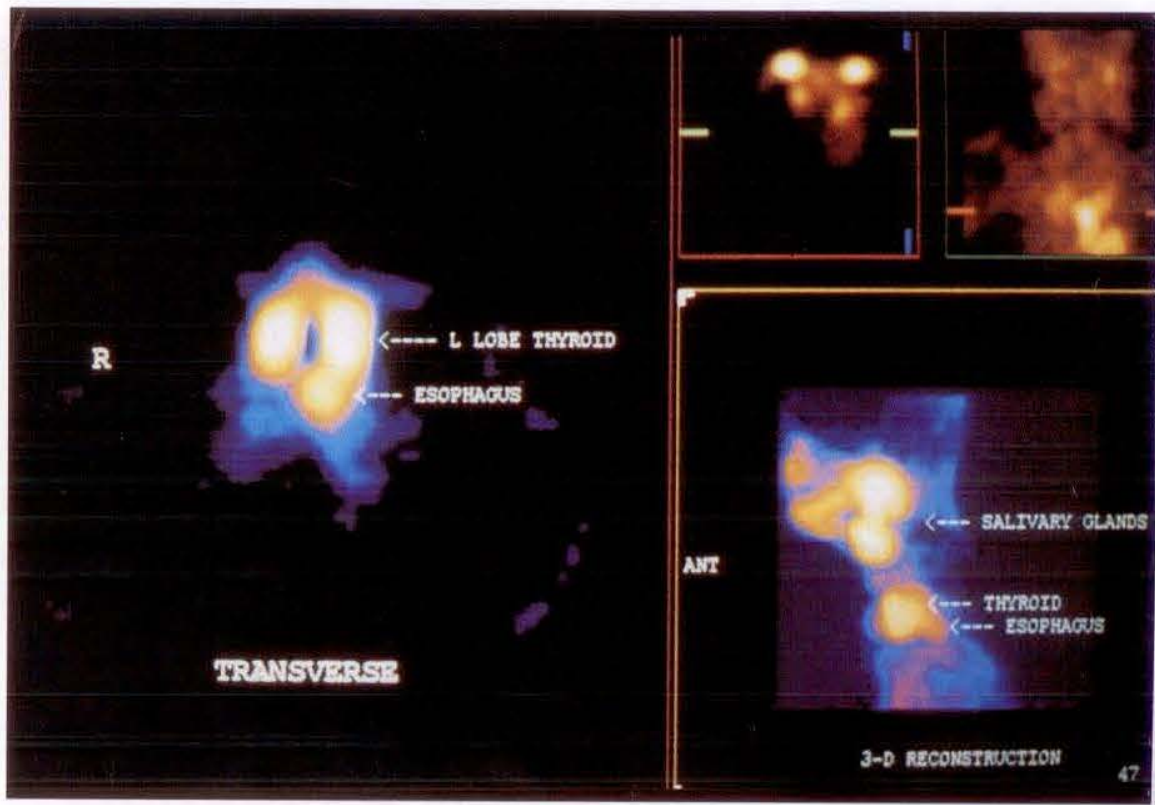

Figure 4) A composite photograph of the gastric mucosal imaging $(99 \mathrm{~m}$ Tc-pertechnetate scintigraphy). On the left is the anterior view of the neck and on the right (lower photograph) is the lateral view, both showing a distinct area of uptake in the cervical esophagus, separate (posterior and inferior) from the thyroid gland

proposed that the UES may form a distinct barrier to reflux and, therefore, ulceration occurs just below the UES, with re-epithelialization of the damaged area with more acid-resistant gastric mucosa (10).

Support for a congenital origin of heterotopic gastric mucosa includes studies of embryology, the low rate of concurrent Barrett's esophagus and the histology of the gastric glands. Embryologically, the patches are felt to be sequestered islands of gastric mucosa remaining in the esophagus after replacement of the early columnar mucosa by stratified squamous epithelium (5). The gastric swelling forms and descends from the 4 to $17 \mathrm{~mm}$ stage in the embryo. By the $40 \mathrm{~mm}$ stage, the stratified columnar epithelium of the primi- 


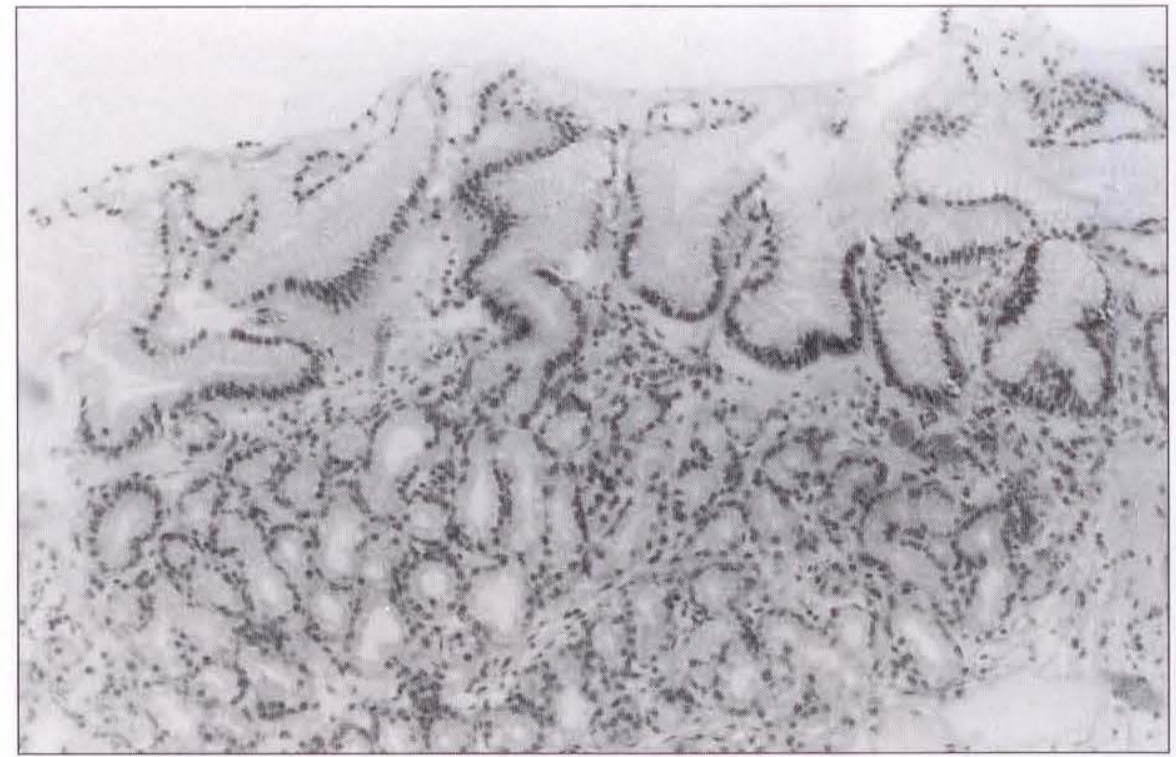

Figure 5) Low power view of the antral type heterotopic gastric mucosa identified in the presented patient (hematoxylin and eosin, $\times 100$ )

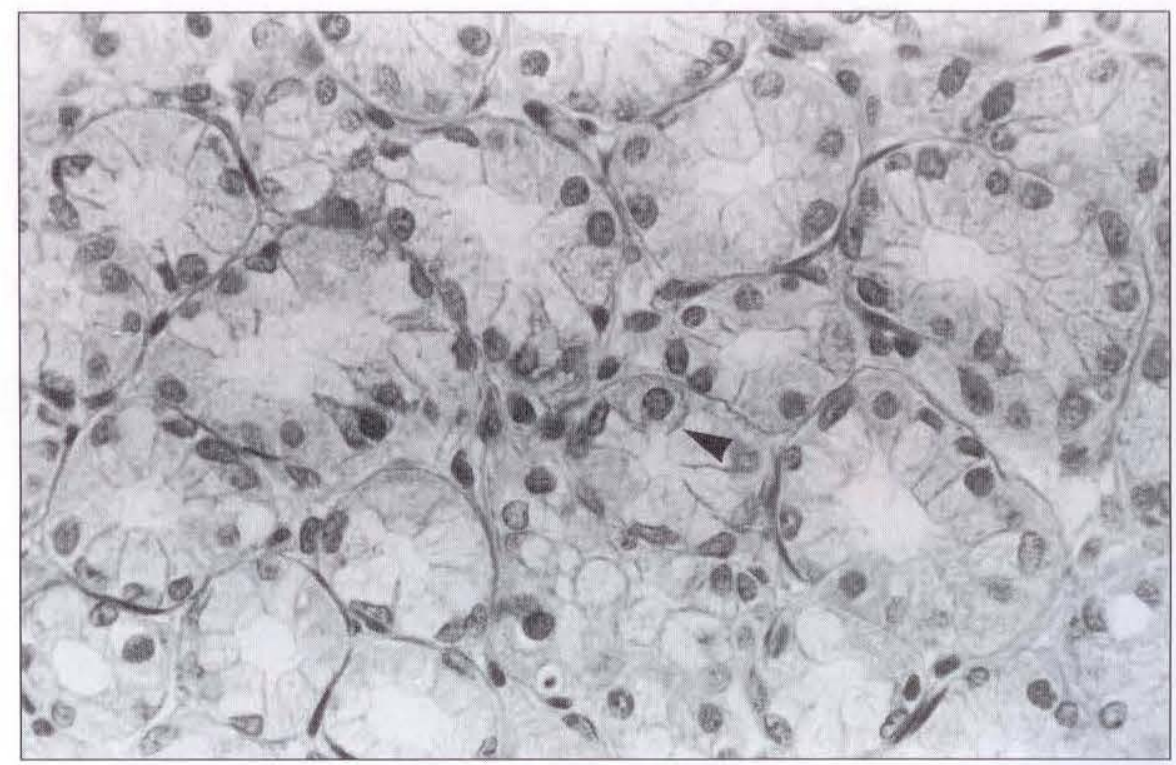

Figure 6) Antral mucosa of the inlet patch showing occasional parietal cells (arrow) and no chief cells (hematoxylin and eosin, $\times 400$ )

tive esophagus is replaced by ciliated columnar epithelium, and by the 130 $\mathrm{mm}$ stage, the ciliated epithelium is replaced by stratified squamous mucosa, first appearing in the middle third of the esophagus and progressing cephalad and caudad (11).

As further support for a congenital origin, concurrent Barrett's esophagus is not frequently identified; only five of 64 patients with gastric mucosa in the upper esophagus had Barrett's change (9) and, in another study, one of 16 cases of heterotopic gastric mucosa had concurrent Barrett's esophagus (8). Comparison of 211 cases of heterotopic gastric mucosa with 354 cases of Barrett's change yielded only 12 patients with both abnormalities (12). In almost all the cases, a different type of gastric mucosa is identified for the upper esophageal patches and Barrett's esophagus, typically fundic glands or, occasionally, antral mucosa is seen in heterotopic gastric mucosa while Barrett's change is usually cardiac-type mucosa (9). In agreement with a congenital origin, our patient was thought to have antral-type gastric mucosa in the cervical esophagus and no evidence of Barrett's esophagus.

Pathology: Heterotopic gastric mucosa may be either localized or circumferential in distribution $(10,13)-45 \%$ are single, while $40 \%$ of the patches are multiple and on opposite sides, and $15 \%$ are multiple and on the same wall of the esophagus (9). The patch in our patient was single and circumferential.

Microscopically, columnar mucosa usually abuts abruptly on squamous mucosa. The appearance of the gastric pits define three types of gastric mucosa that may be identified: first, cardiac zone mucosa containing colloid glands lined with mucous-producing columnar epithelium, and some parietal and chief cells; second, mucosa of the body or fundus of the stomach with straight fundic-type glands containing pepsinsecreting chief cells and acid-secreting parietal cells in the lower half; finally, antral mucosa containing shorter, more tortuous glands full of $\mathrm{G}$ cells, no chief cells and very few parietal cells. Cardiac-type mucosa usually is found with Barrett's esophagus near the gastroesophageal junction. A thin body-type mucosa with fundic glands is seen in $52 \%$ of heterotopic gastric mucosa and a pure antral type in $20 \%$. The remainder of cases represent a mixture of fundic and antral glands (9). About 80 to $90 \%$ of inlet patches contain both parietal and chief cells $(8,14)$. Most of the specimens also show mild to moderate chronic inflammation with lymphocytes and plasma cells, even in the few cases where parietal cells are not identified $(5,8,15)$. In the present case, examination of biopsies of the inlet patch revealed few parietal cells and no chief cells, most consistent with antral mucosa.

Immunoperoxidase staining of lesions appears to lead to a different hormonal profile in symptomatic and asymptomatic patients, although this association was not confirmed in our symptomatic patient (16). Gastrin and bombesin, both staining negative in our patient, are substances known to stimulate acid secretion either directly or indirectly and seem to be found most frequently in symptomatic patients. Somatostatin, staining positive in our 
patient, is known to block acid secretion and is found more frequently in asymptomatic patients.

Presentation: Most people with ectopic gastric mucosa in the upper esophagus are asymptomatic. It would seem that in a minority of cases, some degree of inflammation and ulceration, possibly secondary to trauma or acid secretion, leads to dysphagia with or without complications. Based on the weak Congo red test and the histological finding of only a few parietal cells, it is unlikely that symptoms eventually developed in our patient from acid-induced ulceration. Even if significant acid is secreted, in most cases it appears to be neutralized by swallowed saliva (17). The reason why our patient suddenly became symptomatic after 79 years is unclear.

Recently, a role for campylobacterlike organisms has been proposed in heterotopic gastric mucosa of the upper esophagus (18). Although campylobacter-like organisms are rarely identified (5.3\%), they appear to be associated with severe inflammatory changes in the patch. Unfortunately, no previous studies have attempted to correlate campylobacter-like organisms with symptoms. As our patient's patch was negative for Helicobacter pylori, no further conclusions can be drawn.

Overall, only $9 \%$ of patients with heterotopic gastric mucosa experience pharyngeal discomfort and 6\% complain of high dysphagia (9). The mechanism of the dysphagia, if not accompanied by web formation or stricture, is not completely clear, but has been explained by increased cricopharyngeal UES muscle tone. Very rarely, the patch is pedunculated or polypoid and then may be associated with respiratory symptoms and aspiration $(13,19,20)$.

Diagnosis: Barium swallow will demonstrate no abnormality in uncomplicated heterotopic gastric mucosa, except in the rare situation when the lesion is polypoid. Barium is useful for symptomatic patients to help rule out a stricture, upper esophageal ring (Figure 1) and the rare case of an adenocarcinoma.

Gastroscopy will demonstrate a vel- vety salmon- or red-coloured patch with a distinct border (Figure 2). The upper third of the esophagus is the most neglected area during the procedure and thus inlet patches may easily be missed. Blind introduction of the endoscope misses the area and the endoscope often is withdrawn rapidly at the completion of the procedure without adequate inspection. Repeated contractions of the UES require vigorous air insufflation to visualize the area just below the sphincter (9). Lugol's solution can help to identify a suspected patch. The solution stains squamous mucosa brown, but does not stain the heterotopic gastric mucosa (14). Biopsy serves to confirm further the presence of heterotopic gastric mucosa.

During gastroscopy, acid production by the heterotopic mucosa can be demonstrated by Congo red staining (21). The Congo red technique was used in our patient, but due to the rarity of parietal cells, only a tiny patch of acid production was identified (Figure 4).

$99 \mathrm{~m}$ Tc-pertechnetate scintigraphy has been used to detect ectopic gastric mucosa, but its use has previously been confined to patients with a total thyroidectomy or those taking suppressive thyroid hormone supplements. In patients with a normal thyroid gland, there was overlapping activity between the uptake in the thyroid gland and the ectopic esophageal mucosa, as both lie at the same level (22). As shown in Figure 3, using tomographic technique and three-dimensional reconstruction we were able to demonstrate the patch of heterotopic gastric mucosa in our patient, even though it lay behind a normally functioning thyroid gland.

Complications: Heterotopic gastric mucosa of the upper esophagus can occasionally be complicated by bleeding or formation of a stricture, upper esophageal ring, adenocarcinoma or acquired trachesophageal fistula. Early studies also associate ectopic gastric mucosa with esophageal scars and as lead points for pulsion diverticula.

Strictures are usually smooth and tapering, but must be biopsied to rule out malignancy. A circumferential, rather than localized, distribution of the gas- tric mucosa is associated with stricture formation, probably due to a greater localized reduction in $\mathrm{pH}$ and increase in peptic injury (5). Adenocarcinoma in a focus of ectopic gastric mucosa is exceedingly rare, with most authors doubting its existence. Carrie reported a case within the upper third of the esophagus in 1950 (23). Unlike the acquired Barrett's change, a recent study followed 211 patients with inlet patches for over six years and found that none progressed to adenocarcinoma (12). As a very rare complication, a trachesophageal fistula has been reported secondary to perforation of a peptic ulcer within a patch of heterotopic gastric mucosa (24).

The radiographic and endoscopic appearance in our patient is most consistent with a web or ring formation in the upper esophagus. In 1979, Weaver (10) first described a web in a patch of heterotopic gastric mucosa and proposed it as an alternate explanation for the Paterson-Kelly or Plummer-Vinson syndrome. The article included a case report of an elderly woman with severe dysphagia and a typical upper esophageal web on barium swallow, but no anemia. Gastroscopy revealed heterotopic gastric mucosa with a mucosal ring at the junction of squamous mucosa and the band of gastric mucosa. Similarly, our patient had a web at the junction of squamous and gastric mucosa, and no anemia.

\section{TREATMENT}

In the vast majority of cases, no treatment is necessary. Routine need for follow-up and biopsy, as in Barrett's esophagus, is unnecessary as no proof for progression of the inlet patch to adenocarcinoma has been found (12).

For patients who are symptomatic, or if ulceration or possibly even acid production can be demonstrated on gastroscopy or with Congo red staining, treatment with $\mathrm{H}_{2}$-blockers or omeprazole is warranted $(20,25)$.

Strictures and upper esophageal rings are amenable to endoscopic dilation with good success, as seen in the presented case. Only very rarely will surgical management of complications be necessary. 


\section{REFERENCES}

1. Wolff M. Heterotopic gastric epithelium in the rectum: A report of three new cases with a review of 87 cases of gastric heterotopia in the alimentary canal. Am J Clin Pathol 1971;55:604-16.

2. Kaneko E, Kohda A, Honda N, Kino I. Incomplete tubular duplication of esophagus with heterotopic gastric mucosa. Dig Dis Sci 1989;34:948-51.

3. Emery JL, Haddadin AJ. Gastric-type epithelium in the upper esophageal pouch in children with tracheoesophageal fistula. J Ped Surg 1971;6:449-53.

4. Schmidt FA. De mammalium oesophago atque ventriculo. Inaug Dissert, Halle, in off. Batheana, 1805.

5. Rector LE, Connerley ML. Aberrant mucosa in the esophagus in infants and in children. Arch Path 1941;31:285-94.

6. Schridde H. Uber magenschlelmhaut-Inseln vom bau der cardialdrusenzone und fundus drusenregion und den unteren, oesophagealen cardial drusen gleichen de drusen im obersten oesophagusabschnitt. Virchows Arch Pathol Anat 1904;175:1-16.

7. Variend S, Howat AJ. Upper esophageal gastric heterotopia: A prospective necropsy study in children. J Clin Pathol 1988;41:742-5.

8. Jabbari M, Goresky CA, Lough J, Yaffe C, Daly D, Cote C. The inlet patch: Heterotopic gastric mucosa in the upper esophagus. Gastroenterology 1985;89:352-6.
9. Borhan-Manesh F, Farnum JB. Incidence of heterotopic gastric mucosa in the upper esophagus. Gut 1991;32-968-72.

10. Weaver GA. Upper esophageal web due to a ring formed by the squamocolumnar junction with ectopic gastric mucosa (another explanation of the Paterson-Kelly, Plummer-Vinson Syndrome). Dig Dis Sci 1979;24:959-63.

11. Johns BAE. Developmental changes in the esophageal epithelium in man. J Anat 1952;86:431-42.

12. Ollyo JB, Savary M, Monnier PH, et al. Is heterotopic columnar epithelium in the upper esophagus clinically relevant? Gastroenterology 1988;94:A333.

13. Raine $\mathrm{CH}$. Ectopic gastric mucosa in the upper esophagus as a cause of dysphagia. Ann Otol Rhinol Laryngol 1983;92:65-6.

14. Van Asche C, Rahm AE, Goldner F, Crumbaker D. Columnar mucosa in the proximal esophagus. Gastrointest Endosc 1988;34:324-6.

15. Tchertkoff V, Lee BY. Ulcerative esophagitis with heterotopic gastric mucosa. Am J Gastroenterol 1962;37:174-9.

16. Shah KK, DeRidder PH, Shah KK. Ectopic gastric mucosa in proximal esophagus: Its clinical significance and hormonal profile. J Clin Gastroenterol 1986;8:509-13.

17. Wang MMJ, Spear M, McGrew W. Heterotopic gastric mucosa of the esophagus. South Med J 1986;79:633-5.

18. Flejou JF, Potet F, Molas G.
Campylobacter-like organisms in heterotopic gastric mucosa of the upper esophagus. J Clin Pathol 1990;43:961. (Lett)

19. Powell RW, Luck SR. Cervical esophageal obstruction by ectopic gastric mucosa. J Ped Surg 1988;23:632-4.

20. Libcke JH. Heterotopic gastric mucosa in the cervical esophagus: A possible cause of fatal aspiration. Pediatrics 1969; 44:447-8.

21. Hamilton JW, Thune RG, Morrissey JF. Symptomatic ectopic gastric epithelium of the cervical esophagus: Demonstration of acid production with Congo red. Dig Dis Sci 1986;31:337-42.

22. Chen $\mathrm{CH}$, De Ridder $\mathrm{PH}$, Fink-Bennett D, Alexander TJ. Detection of heterotopic gastric mucosa in the upper esophagus with $99 \mathrm{~m}$ Tc-pertechnectate scintigraphy. J Clin Gastroenterol 1989;11:23-5.

23. Carrie A. Adenocarcinoma of the upper end of the esophagus arising from ectopic gastric epithelium. $\mathrm{Br}$ ] Surg 1950;37:474.

24. Kohler B, Kohler G, Riemann JF. Spontaneous esophagotracheal fistula resulting from ulcer in heterotopic gastric mucosa. Gastroenterology 1988;95:828-30.

25. Truong LD, Stroehlein JR, McKechnie JC. Gastric heterotopia of the proximal esophagus: A report of four cases detected by endoscopy and review of the literature. Am J Gastroenterol 1986; 81:1162-5. 


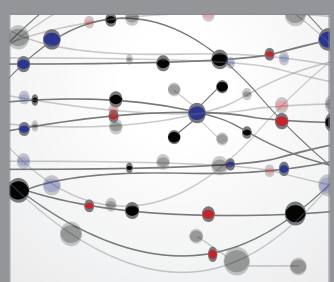

The Scientific World Journal
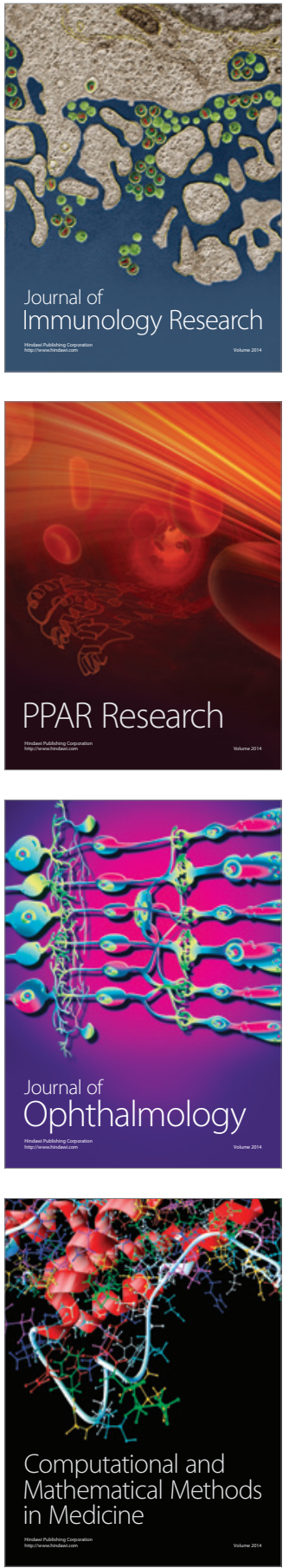

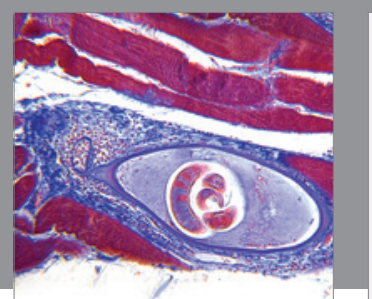

Gastroenterology Research and Practice

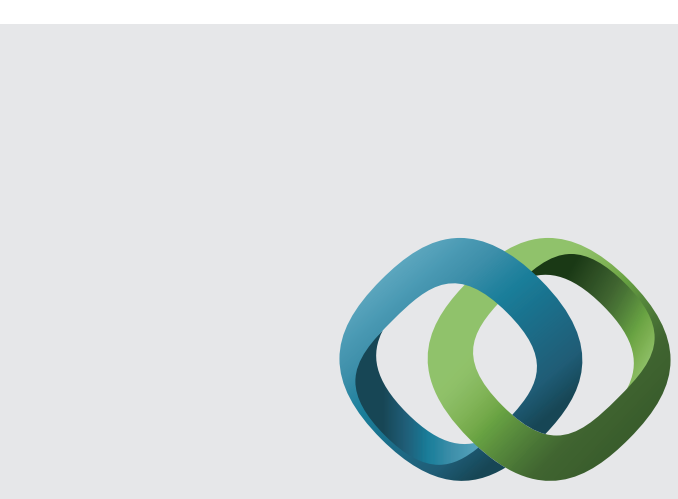

\section{Hindawi}

Submit your manuscripts at

http://www.hindawi.com
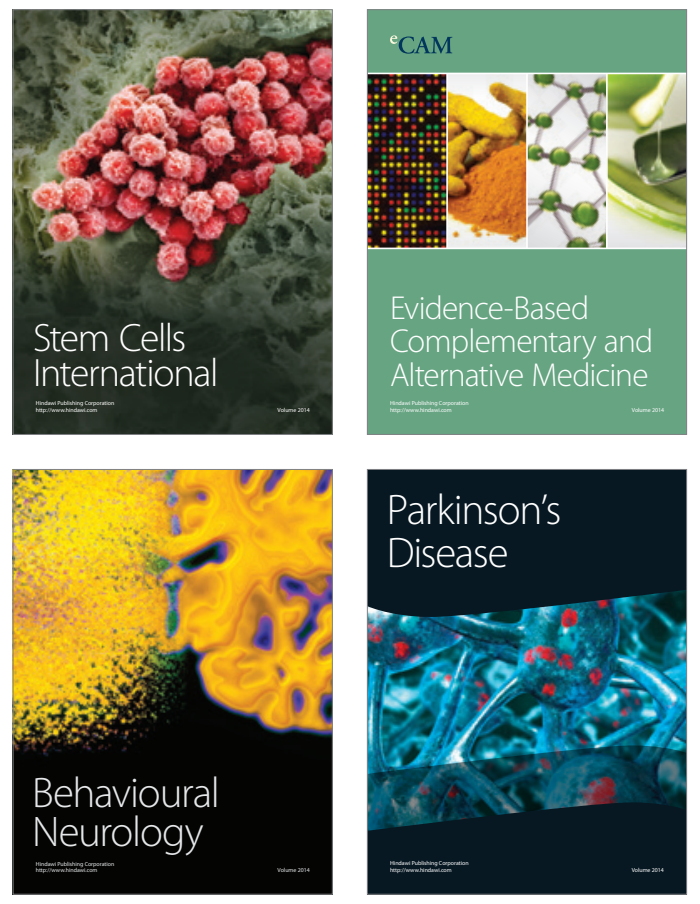
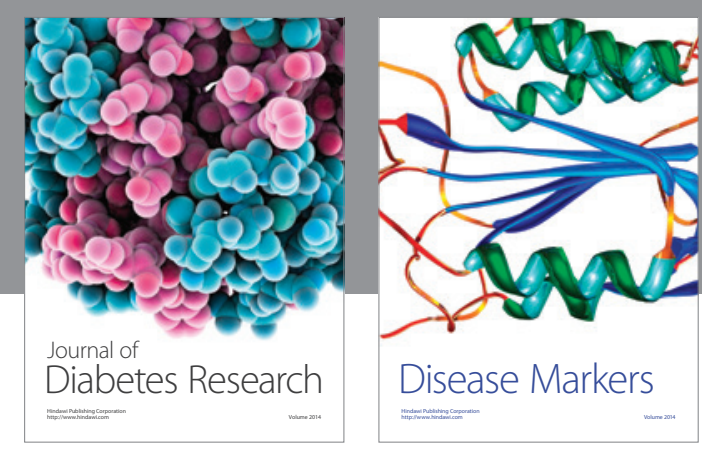

Disease Markers
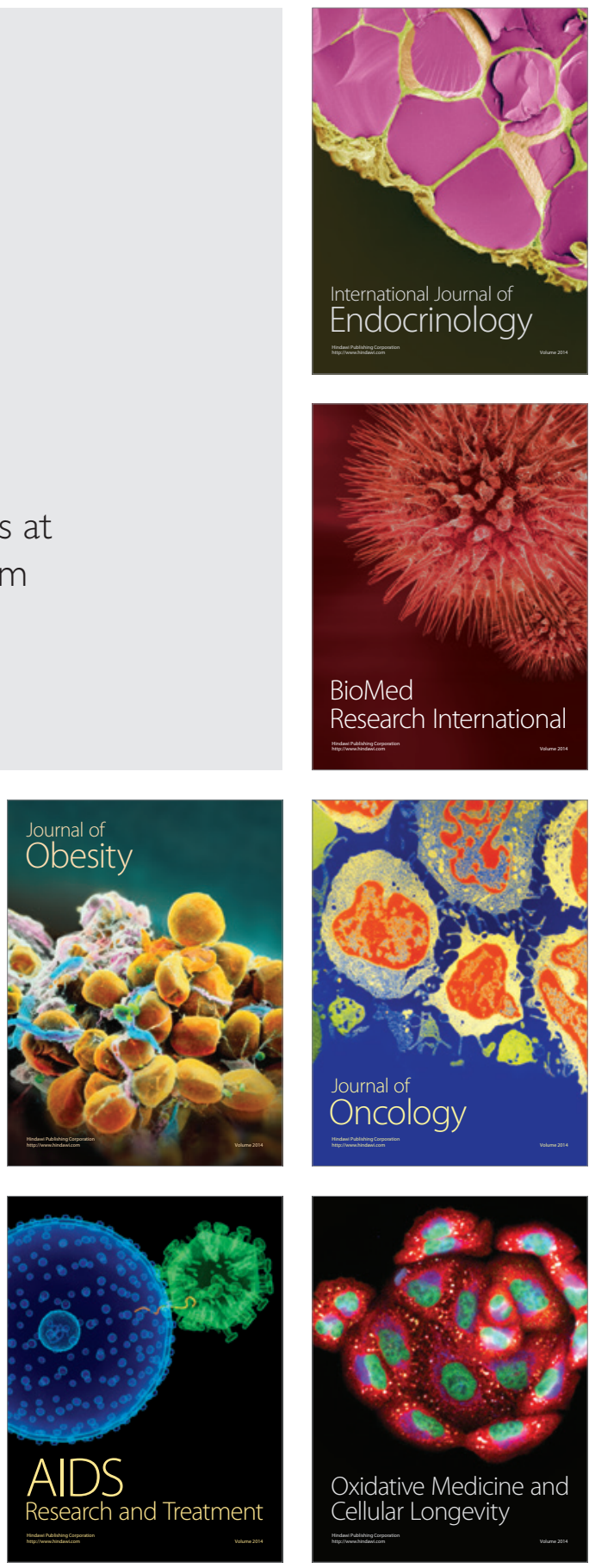